\title{
PENGARUH ALKALINISASI SELULOSA TERHADAP PRODUKSI SODIUM KARBOKSIMETIL SELULOSA
}

\author{
Jamal Basmal', Dina Andhita“', dan Sediarso...)
}

\begin{abstract}
ABSTRAK
Penelitian pemanfaatan limbah pengolahan rumput laut sebagai bahan dasar untuk pembuatan sodium karboksimetil selulosa telah dilakukan. Limbah pengolahan rumput laut Gracilaria verucosa terlebih dahulu diekstrak selulosanya melalui proses pemanasan dalam larutan $\mathrm{NaOH} 40 \%$ (b/v) pada suhu $100^{\circ} \mathrm{C}$ selama 3 jam. Selulosa yang diperoleh kemudian direndam dalam larutan $\mathrm{NaOH} 30 \%, 40 \%, 50 \%$, dan $60 \%$ selama 4 jam pada suhu kamar. Rasio selulosa : Iarutan $\mathrm{NaOH}$ adalah 1:20 (b/v). Proses eterifikasi dilakukan pada suhu $60^{\circ} \mathrm{C}$ selama 2 jam. Nilai sodium karboksimetil selulosa ( $\mathrm{Na}-\mathrm{CMC}$ ) terbaik ditemukan pada perlakuan alkalinisasi selulosa menggunakan larutan $\mathrm{NaOH} 40 \%$ ditinjau dari kandungan $\mathrm{Na}$ dalam $\mathrm{Na}$ CMC sebesar $8,8 \%$, kelarutan membutuhkan $24,8 \mathrm{ml}$ air untuk melarutkan $1 \mathrm{~g} \mathrm{Na}-\mathrm{CMC}$, kekentalan $35 \mathrm{cPs}$, kadar air $9,9 \%$, derajat substitusi 0,8 , kadar abu 1,6\%, kadar abu tak larut asam $0,2 \%$ dengan hasil $82,6 \%$.
\end{abstract}

\begin{abstract}
Effect of cellulose alkalinization on the production of sodium carboxymethyl cellulose. By: Jamal Basmal, Dina Andhita, and Sediarso

Research on utilization of seaweed processing waste as a base product of sodium carboxymethyl cellulose was carried out. Previously cellulose was extracted from waste of seaweed processing Gracilaria verucosa using hot solution of $\mathrm{NaOH} 40 \%$ (W/ $\mathrm{V}$ ) at $100^{\circ} \mathrm{C}$ for 3 hours. The extracted cellulose was then soaked in $\mathrm{NaOH}$ solution of $30 \%, 40 \%, 50 \%$, and $60 \%$ for 4 hours at ambient temperature. Ratio of cellulose: $\mathrm{NaOH}$ solution was 1:20 (w/v). Etherification process was performed at $60^{\circ} \mathrm{C}$ for 2 hours. The best method of Na-CMC production was found by using $40 \% \mathrm{NaOH}$ solution. Properties of $\mathrm{Na}-\mathrm{CMC}$ obtained were $8.8 \%$ sodium content in Na-CMC, $24.8 \mathrm{ml}$ water to dilute $1 \mathrm{~g} \mathrm{Na}-\mathrm{CMC}, 35 \mathrm{cPs}$ viscosity, $9.9 \%$ moisture content, 0.8 degree of substitution, $1.6 \%$ ash content, $1.2 \%$ acid insoluble ash and $82.6 \%$ yield.
\end{abstract}

KEYWORDS: alkalicellulose, sodium carboxymethyl cellulose

\section{PENDAHULUAN}

Pada tanaman baik yang berasal dari daratan maupun laut, selulosa ditemukan bersama-sama dengan bahan lain seperti lignin, hemiselulosa dan pektin serta bahan-bahan anorganik lainnya. Selulosa merupakan polimer alam yang tersusun dari sejumlah unit anhidroglukopiranosa dengan rumus molekul $\left(\mathrm{C}_{6} \mathrm{H}_{10} \mathrm{O}_{5}\right)_{n}$. Nilai $n$ merupakan derajat polimerisasi yaitu jumlah kesatuan berulang dalam polimer (Dyess \& Emert, 1978; Wade \& Weller, 1994). Polimer alam ini mempunyai ikatan antara unit anhidroglukopiranosa satu dengan unit anhidroglukopiranosa lain pada atom C nomor satu $\left(C_{1}\right)$ dan atom $C$ nomor empat $\left(C_{4}\right)$ dalam bentuk $\beta$-glikosida atau ikatan $(1 \rightarrow 4) \beta$ glikosida (Fengel \& Wegner, 1984; Cowd, 1991). Selulosa banyak dijumpai pada tumbuhan tingkat tinggi (embryophyta) dan hampir seluruh tumbuhan tingkat rendah (thallophyta), yaitu sebagai struktur penguat dinding sel pada tumbuhan.

Pada umumnya kandungan selulosa pada dinding sel rumput laut sebesar $30 \%$, tumbuhan tahunan $25 \%$ sampai $35 \%$ dan pohon $40 \%$ sampai $50 \%$ (Parker, 1992; Wade \& Weller, 1994). Selulosa banyak digunakan sebagai anti-penjendalan (anticake agents) emulsifier, stabilizer, agen dispersi, pengental (thickener), dan gelling agent. Selulosa dalam bentuk khusus amorphous cellulose dapat menyerap air menjadi lunak dan fleksibel. Air yang ada di dalam selulosa pada saat pencampuran tidak bercampur sempurna melainkan sejumlah air hanya terperangkap di dalam sel selulosa. Sebagian kecil air terikat secara langsung pada ikatan hidrogen jika selulosa dalam bentuk kristal (high crystallinity). Tetapi jika selulosa dalam bentuk serat (fiber), sejumlah air akan masuk di antara pori-pori selulosa sehingga

\footnotetext{
-) Peneliti pada Pusat Riset Pengolahan Produk dan Sosial Ekonomi Kelautan dan Perikanan

*) Mahasiswa S1 Fakultas Farmasi, Universitas Pancasila

*.) Dosen Universitas Pancasila
} 
membentuk straw-like cavities. Kemampuan mengikat air (water holding ability) berhubungan kuat dengan amorphous cellulose.

Tiap unit anhidroglukosa pada selulosa mengandung tiga gugus hidroksil; yaitu satu gugus hidroksil primer pada atom $\mathrm{C}_{6}\left(-\mathrm{CH}_{2} \mathrm{OH}\right)$ dan dua gugus hidroksil $(\mathrm{OH})$ sekunder pada atom $\mathrm{C}_{2}$ dan $\mathrm{C}_{3}$. Secara teoritis adanya kandungan gugus hidroksil menyebabkan suatu senyawa dapat larut dalam air. Akan tetapi, kenyataannya tidak demikian. Selulosa bukan saja tidak larut dalam air tetapi juga tidak larut dalam pelarut organik dan anorganik. Hal ini disebabkan karena adanya ikatan hidrogen antara gugus hidroksil pada rantai yang berdekatan sehingga membentuk struktur yang kaku dan memberikan kristalinitas yang tinggi.

Meskipun selulosa tidak larut dalam air, tetapi banyak turunan selulosa yang dapat larut dalam air yaitu dengan cara mereaksikan gugus hidroksil pada selulosa melalui proses eterifikasi atau esterifikasi (Cowd, 1991). Selulosa murni yang dinyatakan sebagai a-selulosa merupakan bagian selulosa yang tidak larut dalam basa kuat. Selulosa murni atau a-selulosa inilah yang dapat digunakan sebagai bahan dasar untuk pembuatan turunan selulosa. Dalam pembentukan turunan selulosa, a-selulosa harus diikat dengan larutan basa kuat yang bertujuan memperlemah ikatan gugus hidroksil primer pada atom $\mathrm{C}_{6}$. Salah satu turunan selulosa yang banyak diproduksi adalah sodium karboksimetilselulosa ( $\mathrm{Na}-\mathrm{CMC}$ ).

Sifat dari $\mathrm{Na}-\mathrm{CMC}$ adalah transparan, tidak berwarna, tidak beracun, larut air pada $\mathrm{pH} 6,5-8,0$, stabil pada $\mathrm{pH} 2-10$, tidak larut dalam pelarut organik, dapat bereaksi dengan garam logam berat dan membentuk lapisan film tipis yang tidak larut di dalam air. Sedangkan kegunaannya sebagai bahan dasar deterjen, sabun, produk makanan khususnya makanan diet (dietetic foods), dan es krim yang berfungsi sebagai pengikat air, pengental (thickener), suspensi, emulsifier dan stabilizer serta dapat memperbaiki volume dan tekstur khususnya sebagai pengganti lemak dalam pembuatan saus dan makanan ringan. Di dalam industri tekstil berfungsi sebagai seizing, pelapis kertas dan paper board untuk menurunkan porositas, sebagai lumpur pengeboran minyak (drilling muds), emulsi cat, pelindung koloid, farmasi, dan kosmetik.

Tujuan pembuatan $\mathrm{Na}-\mathrm{CMC}$ ini adalah untuk memanfaatkan semaksimal mungkin limbah pengolahan rumput laut sehingga dapat meningkatkan efisiensi di dalam pengolahan rumput laut.

Proses pembuatan $\mathrm{Na}-\mathrm{CMC}$ adalah melalui proses alkalinisasi yang selanjutnya dieterifikasi menggunakan asam monokloro asetat atau sodium monokloro asetat atau metil khlorida pada waktu dan suhu tertentu. Jenis bahan kimia yang umum digunakan pada proses alkalinisasi selulosa adalah sodium hidroksida $(\mathrm{NaOH})$. Hal ini disebabkan $\mathrm{NaOH}$ mempunyai sifat mudah larut di dalam air, alkohol, dan gliserin serta mempunyai sifat basa yang kuat (Fengel \& Wegner, 1984).

\section{BAHAN DAN METODE}

Bahan yang digunakan dalam penelitian ini adalah limbah pengolahan agar-agar dari rumput laut Gracilaria verucosa. Limbah tersebut sebelum diolah dikeringkan terlebih dahulu kemudian dilakukan proses pemurnian selulosa. Teknik pembuatan selulosa mengadopsi metoda Goplin (2003) yakni pemasakan bahan baku dalam larutan $\mathrm{NaOH}$, penetralan dan pemutihan. Teknik pemurnian selulosa dilakukan dengan cara sebagai berikut: limbah rumput laut yang akan diolah terlebih dahulu dikeringkan, kemudian dilakukan proses pemasakan menggunakan larutan $\mathrm{NaOH} 20 \%, 30 \%, 40 \%$, dan $50 \%$ (b/v) dengan rasio limbah pengolahan rumput laut : Iarutan $\mathrm{NaOH}$ (1:20). Hasil terbaik berdasarkan jumlah $\alpha$-selulosa yang dihasilkan ditemukan pada proses pemasakan dalam larutan $\mathrm{NaOH} 40 \%$ pada suhu $100^{\circ} \mathrm{C}$ selama 3 jam.

Pada proses pembuatan $\mathrm{Na}-\mathrm{CMC}$, limbah rumput laut yang telah dimasak dalam larutan $\mathrm{NaOH} 40 \%$ pada suhu $100^{\circ} \mathrm{C}$ selama 3 jam, kemudian dicuci sampai netral $(\mathrm{pH} 7)$ dan dipucatkan menggunakan larutan $\mathrm{H}_{2} \mathrm{O}_{2} 6 \%$. Proses pembuatan $\mathrm{Na}-\mathrm{CMC}$ ini mengadopsi metode penelitian Manguiat et al. (2001) yakni selulosa direndam dalam larutan $\mathrm{NaOH}$, untuk penetapan nilai $\mathrm{pH}$ selanjutnya ditambahkan monokloro asetat secara perlahan-lahan pada suhu tertentu. Bahan yang telah dipucatkan selanjutnya dibilas dan dikeringkan kemudian dilanjutkan proses penepungan. Limbah rumput laut yang telah dihilangkan dari zat-zat nonselulosa kemudian dilanjutkan proses alkalinisasi menggunakan larutan sodium hidroksida pada konsentrasi $30 \%, 40 \%, 50 \%$, dan $60 \%$ (b/v) dengan rasio selulosa : Iarutan $\mathrm{NaOH}$ sebesar 1:20. Proses alkalinisasi dilakukan selama 4 jam. Selulosa yang telah dialkalinisasi kemudian dilanjutkan proses eterifikasi menggunakan asam monokloro asetat pada suhu $60^{\circ} \mathrm{C}$ selama 120 menit. Untuk menetralkan kelebihan asam dari monokloro asetat ditambahkan larutan $\mathrm{NaOH}$ hingga $\mathrm{pH}$ netral. Larutan sodium karboksimetil selulosa ( $\mathrm{Na}-\mathrm{CMC}$ ) yang terbentuk kemudian ditarik menggunakan isopropyl alcohol (IPA) dengan rasio 1:2 (1 bagian larutan $\mathrm{Na}-\mathrm{CMC}$ : 2 bagian IPA). Serat $\mathrm{Na}-\mathrm{CMC}$ selanjutnya dikeringkan dan kemudian dijadikan tepung $\mathrm{Na}-\mathrm{CMC}$. Untuk mendapatkan ketelitian maka proses 
pembuatan $\mathrm{Na}-\mathrm{CMC}$ dilakukan sebanyak 3 kali ulangan.

Analisis yang dilakukan terhadap $\mathrm{Na}-\mathrm{CMC}$ yang dihasilkan meliputi: uji kualitatif $\mathrm{Na}-\mathrm{CMC}$ (Anon. 1995), penetapan kadar Na-CMC, kelarutan, kekentalan yang diukur pada konsentrasi $1 \%$ dengan alat Viskometer Brookfield menggunakan spindel nomor 2 dan kecepatan $30 \mathrm{rpm}$ pada suhu kamar (Anon., 1981), kadar air (Anon., 1995), derajat substitusi (Anon., 1981), kadar abu, dan kadar abu tak larut asam (Anon., 1981).

\section{HASIL DAN BAHASAN}

\section{Uji Kualitatif Na-CMC}

Uji kualitatif terhadap Na-CMC yang dibuat dari selulosa yang berasal dari limbah pembuatan agaragar adalah menggunakan larutan 1-naftol dan asam sulfat pekat yang memperlihatkan adanya warna merah ungu pada bidang batas antara dua lapisan.
Sedangkan pada pengujian menggunakan larutan barium klorida terbentuk endapan warna putih. Hasil kedua pengujian membuktikan bahwa bahan yang diperiksa mempunyai identitas sesuai dengan yang dimiliki oleh $\mathrm{Na}-\mathrm{CMC}$. Hasil analisis uji kualitatif $\mathrm{Na}$ CMC berdasarkan Farmakope Indonesia dapat dilihat pada Tabel 1.

Pada Tabel 1 dapat dilihat bahwa $\mathrm{Na}-\mathrm{CMC}$ yang dibuat dari selulosa yang berasal dari limbah pembuatan agar, menunjukkan hasil positif (+). Dengan demikian Na-CMC tersebut memenuhi persyaratan yang ditetapkan oleh Farmakope Indonesia (Anon., 1995).

\section{Rendemen Na-CMC}

Hasil Na-CMC yang diperoleh berkisar antara $54,1 \%-91,5 \%$. Nilai tertinggi ditemukan pada perlakuan alkalinisasi menggunakan larutan $\mathrm{NaOH}$ $30 \%$ dan terkecil pada perlakuan alkalinisasi menggunakan larutan $\mathrm{NaOH} 60 \%$. Pada Gambar 1

Tabel 1. Hasil analisis kualitatif $\mathrm{Na}-\mathrm{CMC}$

Table 1. Qualitative analysis of $\mathrm{Na}-\mathrm{CMC}$

Prosedur analisa/Step of analysis

Hasil/Results

Keterangan/

Explanation

\begin{tabular}{|c|c|c|}
\hline $\begin{array}{l}\text { Larutan sampel ditambah dengan 1-naftol LP dan } \\
\text { asam sulfat pekat/Sample solution was added with } \\
\text { 1-naftol LP and concentrated sulfuric acid }\end{array}$ & $\begin{array}{l}\text { Warna merah ungu pada bidang } \\
\text { batas antara dua lapisan/Red } \\
\text { purplish between two layers }\end{array}$ & + \\
\hline $\begin{array}{l}\text { Larutan sampel ditambah dengan larutan barium } \\
\text { klorida/Sample solution was added with barium } \\
\text { chloride solution }\end{array}$ & Endapan putih White precipitate & + \\
\hline
\end{tabular}

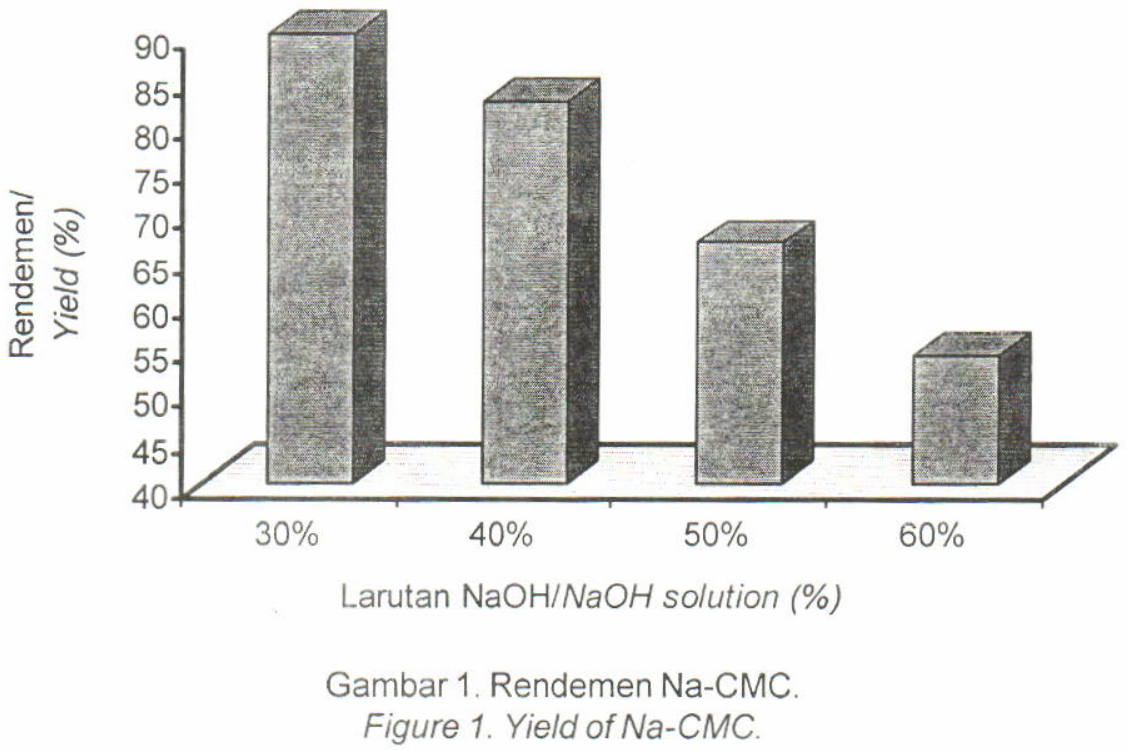


dapat dilihat hasil Na-CMC setiap perlakuan setelah proses eterifikasi menggunakan larutan asam monokloro asetat.

Konsentrasi $\mathrm{NaOH}$ yang digunakan pada proses alkalinisasi selulosa berpengaruh sangat nyata terhadap Na-CMC yang dihasilkan. Nilai Na-CMC semakin menurun dengan peningkatan konsentrasi larutan $\mathrm{NaOH}$ yang digunakan. Hasil uji korelasi antar perlakuan larutan $\mathrm{NaOH}$ ditemukan nilai persamaan garis linier $Y=-12,784 X+105,61$ dengan nilai $r^{2}$ sebesar 0,9898. Pada persamaan garis tersebut dapat diinterpretasikan bahwa ternyata peningkatan konsentrasi larutan $\mathrm{NaOH}$ selama proses alkalinisasi dapat menurunkan hasil $\mathrm{Na}-\mathrm{CMC}$ yang diperoleh secara linier.

Penurunan hasil $\mathrm{Na}-\mathrm{CMC}$ tersebut diduga karena pada pemakaian sodium hidroksida dengan konsentrasi yang semakin tinggi menyebabkan so$\operatorname{dium}(\mathrm{Na})$ dari sodium hidroksida tidak hanya bereaksi titrasi bebas air secara asidimetri dapat dilihat pada Tabel 2.

Pada Tabel 2 dapat dilihat bahwa kadar Na-CMC pada perlakuan dengan konsentrasi sodium hidroksida $30 \%$ pada tahap alkalinisasi memberikan hasil di bawah kadar yang ditetapkan, yaitu 6,40\% dihitung berdasarkan $\mathrm{Na}$. Sebaliknya, pemakaian konsentrasi sodium hidroksida lebih dari $40 \%$, yaitu $50 \%$ dan $60 \%$ memberikan hasil di atas nilai kadar yang ditetapkan yaitu $11,30 \%$ dan $12,50 \%$ dihitung berdasarkan so$\operatorname{dium}(\mathrm{Na})$.

Rendahnya kadar Na-CMC pada pemakaian sodium hidroksida $30 \%$ diduga karena proses pertukaran ion $\mathrm{Na}^{+}$dengan gugus hidroksil pada atom $\mathrm{C}_{6}\left(-\mathrm{CH}_{2} \mathrm{OH}\right)$ dan dua gugus hidroksil $\left(\mathrm{OH}^{-}\right)$sekunder pada atom $\mathrm{C}_{2}$ dan $\mathrm{C}_{3}$ tidak cukup kuat untuk melepaskan gugus hidroksil sehingga pada proses eterifikasi tidak banyak gugus karboksimetil dari asam monokloro asetat yang berikatan pada atom $\mathrm{C}_{2}, \mathrm{C}_{3}$ dan $\mathrm{C}_{6}$. Sebaliknya,

Tabel 2. Kadar Na-CMC

Tabel 2. Sodium carboxylmethyl cellulose content

\begin{tabular}{ccc}
\hline $\begin{array}{c}\text { Konsentrasi } \mathrm{NaOH} / \\
\mathrm{NaOH} \text { Concentration } \\
(\%)\end{array}$ & $\begin{array}{c}\text { Kadar Na-CMC berdasarkan Na/ } \\
\text { Na-CMC content based on Na (\%) }\end{array}$ & $\begin{array}{c}\text { Standar/Standard }{ }^{*} \\
\text { (\%) }\end{array}$ \\
\hline 30 & $6.40 \pm 0.015$ & \\
40 & $8.78 \pm 0.040$ & $6.5-9.5$ \\
50 & $11.30 \pm 0.050$ & \\
60 & $12.50 \pm 0.015$ & \\
\hline
\end{tabular}

*) Sumber/Source: Anon. (1995).

dengan gugus hidroksil pada atom $\mathrm{C}_{6}$, tetapi juga pada atom $\mathrm{C}_{2}$. Apabila substitusi gugus karboksimetil terjadi juga pada atom $\mathrm{C}_{3}$ akan mengakibatkan semakin banyak jumlah gugus hidroksil yang disubstitusi oleh gugus karboksimetil dari asam monokloro asetat (Brandt et al., 2003). Oleh karena semakin banyak gugus hidroksil yang tersubstitusikan oleh gugus karboksimetil, kelarutan zat dalam air semakin meningkat dan bersifat lebih polar sehingga pada tahap pemurnian dengan metanol, $\mathrm{Na}-\mathrm{CMC}$ yang mengalami substitusi pada $\mathrm{C}_{2}$ dan $\mathrm{C}_{6}$ menjadi sedikit yang dapat diendapkan.

\section{Kadar Na-CMC}

Analisis kadar Na-CMC merupakan salah satu syarat mutu yang harus dipenuhi di dalam Farmakope Indonesia yaitu tidak kurang dari 6,5\% dan tidak lebih dari $9,5 \%$ dihitung terhadap bobot bahan kering. Hasil analisis kadar $\mathrm{Na}-\mathrm{CMC}$ yang dihitung terhadap kadar sodium $(\mathrm{Na})$ dengan metode tingginya kadar $\mathrm{Na}-\mathrm{CMC}$ di atas nilai yang dipersyaratkan yaitu pada pemakaian konsentrasi sodium hidroksida $50 \%$ dan $60 \%$ diduga karena sodium dari sodium hidroksida tidak hanya bereaksi dengan gugus hidroksil pada atom $\mathrm{C}_{6}$ tapi juga pada atom $\mathrm{C}_{2}$ sehingga diperoleh $\mathrm{Na}-\mathrm{CMC}$ yang mengalami substitusi pada $\mathrm{C}_{2}, \mathrm{C}_{3}$ dan $\mathrm{C}_{6}$. Dengan demikian kadar $\mathrm{Na}-\mathrm{CMC}$ yang dihitung terhadap Na yang memenuhi persyaratan Farmakope Indonesia (Anon., 1995) adalah pada pemakaian konsentrasi sodium hidroksida $40 \%$ pada tahap alkalinisasi, yaitu $8,78 \%$.

\section{Kelarutan dalam Air}

$\mathrm{Na}-\mathrm{CMC}$ merupakan turunan dari selulosa yang mudah terdispersi dalam air membentuk larutan koloidal. Data mengenai kelarutan sodium hidroksida di dalam air dapat dilihat pada Tabel 3.

Berdasarkan data pada Tabel 3 dapat dilihat bahwa kelarutan $\mathrm{Na}-\mathrm{CMC}$ yang dibuat dengan menggunakan sodium hidroksida $30 \%$ kurang memberikan hasil yang 
Tabel 3. Kelarutan Na-CMC dalam air

Table 3. Na-CMC solubility in water

\begin{tabular}{ccc}
\hline $\begin{array}{c}\text { Konsentrasi } \mathrm{NaOH} / \\
\mathrm{NaOH} \text { Concentration } \\
\text { (\%) }\end{array}$ & $\begin{array}{c}\text { Jumlah air untuk melarutkan } \\
1 \mathrm{~g} \mathrm{Na}-\mathrm{CMC} / \text { Total volume } \\
\text { of water to dilute } 1 \mathrm{~g} \mathrm{Na}- \\
\mathrm{CMC}(\mathrm{mL})\end{array}$ & $\begin{array}{c}\text { Keterangan/ } \\
\text { Explanation }\end{array}$ \\
\hline 30 & $46.84 \pm 0.014$ & $\begin{array}{c}\text { Agak sukar larut/ } \\
\text { Slightly soluble } \\
\text { Larut/Soluble }\end{array}$ \\
40 & $24.84 \pm 0.011$ & Larut/Soluble \\
50 & $20.31 \pm 0.079$ & Larut/Soluble \\
\hline
\end{tabular}

baik, karena pada pemakaian sodium hidroksida pada konsentrasi tersebut dihasilkan larutan Na-CMC yang agak sukar larut dalam air. Hal ini diduga bahwa pada konsentrasi sodium hidroksida $30 \%$ proses eterifikasi yaitu substitusi gugus hidroksil dengan gugus karboksimetil kurang berjalan baik. Sebaliknya, kelarutan $\mathrm{Na}-\mathrm{CMC}$ pada pemakaian sodium hidroksida yang lebih tinggi $(40 \%, 50 \%$, dan $60 \%)$ memberikan hasil yang lebih baik yaitu Na-CMC yang larut dalam air. Peningkatan kelarutan ini disebabkan oleh jumlah ion sodium yang berikatan dengan selulosa lebih banyak sehingga pada proses eterifikasi jumlah gugus karboksimetil (- $\mathrm{CH}_{2} \mathrm{COO}$ ) yang berikatan dengan ion sodium pada atom $\mathrm{C}_{6}\left(-\mathrm{CH}_{2} \mathrm{OONa}\right)$ dari selulosa lebih banyak. Dengan demikian semakin banyak gugus hidroksil yang tersubstitusi oleh gugus karboksimetil, kelarutan $\mathrm{Na}-\mathrm{CMC}$ dalam air semakin meningkat. Proses pembentukan Na-CMC dapat dilihat pada diagram di bawah ini.

$$
\begin{aligned}
& \text { Selulosa- }(\mathrm{OH})+\mathrm{NaOH} \\
& \text { Selulosa- }(\mathrm{ONa})+\mathrm{ClCH}_{2} \mathrm{COOH} \\
& \mathrm{ClCH}_{2} \mathrm{COOH}+2 \mathrm{NaOH}
\end{aligned}
$$

Ion $\mathrm{Na}^{+}$merupakan garam yang berwarna putih, bersifat basa kuat, mudah menyerap karbon dioksida, mudah menyerap air sambil mengeluarkan panas bila dilarutkan di dalam air, tetapi dalam alkohol atau gliserin meskipun mudah larut tidak mengeluarkan panas (Anon., 2004). Gugus hidroksil pada struktur selulosa merupakan asam lemah sehingga pada konsentrasi larutan $\mathrm{NaOH}$ tertentu akan menghasilkan alkoksida selulosa. Dalam pembuatan $\mathrm{Na}-\mathrm{CMC}$, ion $\mathrm{Na}^{+}$hanya diharapkan bereaksi pada atom $\mathrm{C}_{6}$ dan $\mathrm{C}_{2}$, apabila konsentrasi $\mathrm{NaOH}$ yang diberikan terlalu tinggi akan bereaksi pada atom $\mathrm{C}_{3}$. Alkoksida selulosa yang terbentuk ini bersifat lebih reaktif sehingga apabila direaksikan dengan asam organik seperti metil khlorida atau asam monokloro asetat, akan mudah mensubstitusi gugus karboksimetil dari asam monokloro asetat membentuk Na-CMC. Semakin banyak gugus metilkarboksil yang bereaksi dengan alkoksida selulosa Na-CMC akan semakin mudah larut di dalam air (Klug, 1995). Hasil percobaan membuktikan bahwa peningkatan konsentrasi larutan $\mathrm{NaOH}$ selama proses alkalinisasi selulosa semakin meningkatkan ion $\mathrm{Na}^{+}$yang berikatan dengan selulosa sehingga pada proses lanjutan (eterifikasi) jumlah gugus karboksimetil dari asam monokloro asetat banyak yang terikat dengan ion $\mathrm{Na}^{+}$sebagai akibatnya $\mathrm{Na}-\mathrm{CMC}$ yang terbentuk semakin banyak

\section{Nilai Kekentalan}

Hasil pengukuran kekentalan larutan Na-CMC disajikan dalam bentuk grafik pada Gambar 2.

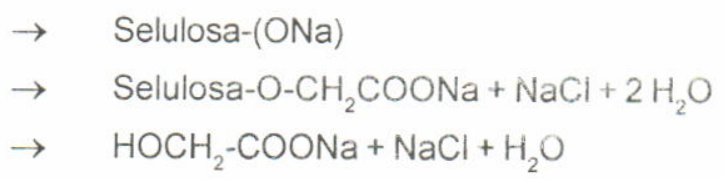

Pemakaian konsentrasi sodium nidroksida dari $30 \%$ ke $40 \%$ menyebabkan peningkatan kekentalan larutan Na-CMC dari 29 cPs menjadi 35 cPs. Sebaliknya, pemakaian konsentrasi sodium hidroksida yang lebih tinggi yaitu dari $40 \%$ ke $50 \%$ dan $50 \%$ ke $60 \%$ menyebabkan penurunan kekentalan yang cukup drastis dari 35 cPs menjadi 19,50 cPs dan dari 19,50 cPs menjadi 10 cPs. Penurunan kekentalan ini diduga karena semakin tinggi pemakaian konsentrasi sodium hidroksida semakin banyak gugus karboksimetil dari asam monokloro asetat yang berikatan dengan ion $\mathrm{Na}^{+}$dari selulosa-(ONa) sehingga menyebabkan kelarutan Na-CMC di dalam air meningkat. 


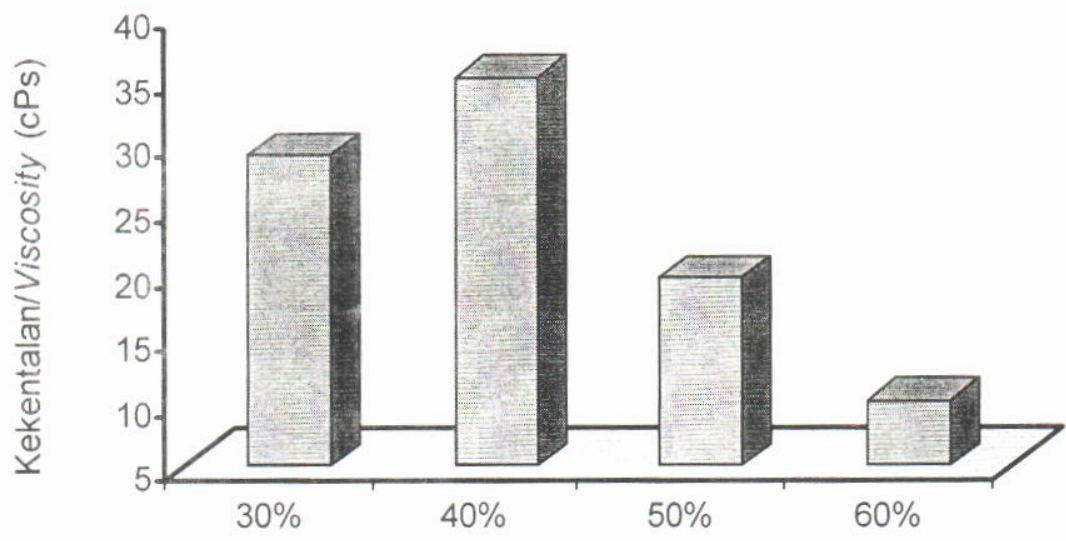

Konsentrasi $\mathrm{NaOH} /$ Concentration of $\mathrm{NaOH}$

Gambar 2. Nilai kekentalan Na-CMC

Figure 2. Viscosity of $\mathrm{Na}-\mathrm{CMC}$.

Peningkatan kelarutan ini menyebabkan semakin kecilnya tahanan dari suatu cairan untuk mengalir, sehingga kekentalannya menjadi menurun.

Kekentalan Na-CMC juga merupakan salah satu syarat mutu yang harus dipenuhi di dalam Farmakope Indonesia. Nilai kekentalan $\mathrm{Na}-\mathrm{CMC}$ yang dipersyaratkan adalah tidak boleh kurang dari $25 \mathrm{cPs}$ (Anon., 1995). Dengan demikian kekentalan $\mathrm{Na}$-CMC yang memenuhi persyaratan adalah pada pemakaian sodium hidroksida $30 \%$ dan $40 \%$ pada proses alkalinisasi.

\section{Kadar Air}

Analisis penetapan kadar air dilakukan untuk mengetahui kadar zat yang mudah menguap, termasuk pelarut organik dan air yang terkandung dalam Na-CMC. Nilai kadar air Na-CMC yang dihasilkan berkisar antara $9,22 \%-9,86 \%$ dengan nilai terendah pada perlakuan alkalinisasi selulosa menggunakan larutan $30 \% \mathrm{NaOH}$, sedangkan yang tertinggi pada perlakuan alkalinisasi selulosa menggunakan larutan 40\% NaOH. Pada Gambar 3 dapat dilihat kadar air dari masing-masing perlakuan.

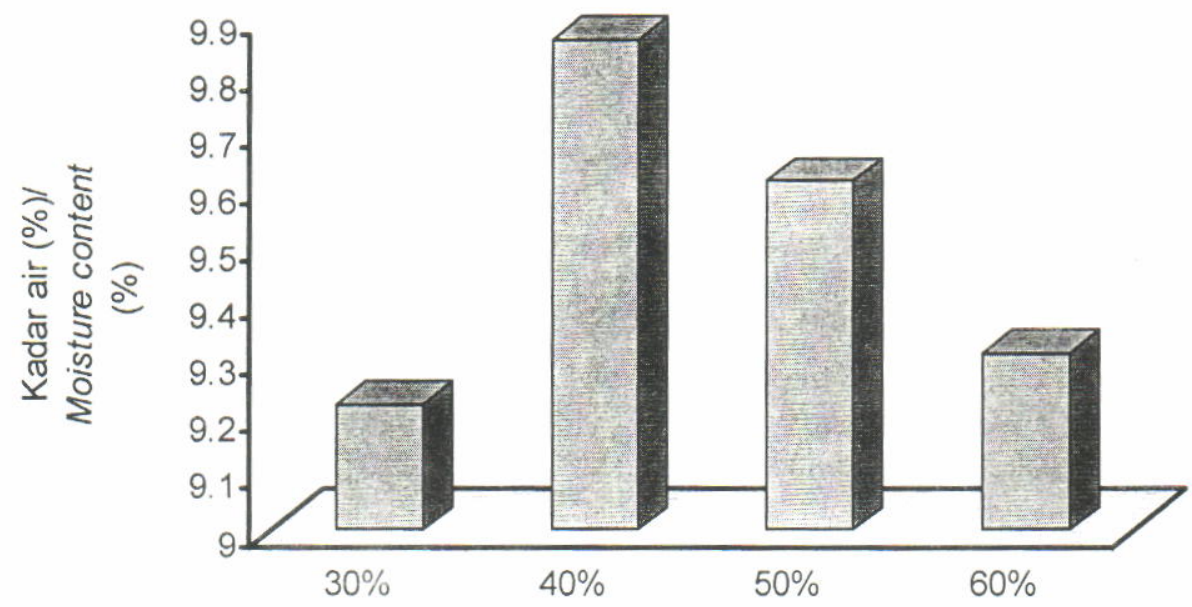

Konsentrasi $\mathrm{NaOH} /$ Concentration of $\mathrm{NaOH}$

Gambar 3. Kadar air Na-CMC.

Figure 3. Moisture content of $\mathrm{Na}-\mathrm{CMC}$. 
Nilai kadar air $\mathrm{Na}-\mathrm{CMC}$ yang disyaratkan dalam Farmakope Indonesia adalah tidak boleh lebih dari $10 \%$. Dengan demikian kadar air $\mathrm{Na}-\mathrm{CMC}$ yang dihasilkan dalam penelitian ini masih memenuhi syarat yang ditetapkan oleh Farmakope Indonesia (Anon., 1995).

\section{Derajat Substitusi}

Hasil analisis derajat substitusi (DS) untuk semua perlakuan berkisar antara 0,74-1,14 dengan nilai terendah ditemukan pada perlakuan alkalinisasi menggunakan larutan $\mathrm{NaOH} 30 \%$ dan yang tertinggi pada perlakuan dengan larutan $\mathrm{NaOH} 60 \%$. Nilai DS diperoleh persamaan garis polynomial $Y=0,0125 X^{2}+$ $0,0765 X+0,6425$ dengan nilai $r^{2}$ sebesar 0,9854 . Dapat disimpulkan bahwa alkalinisasi selulosa sangat berpengaruh terhadap peningkatan derajat substitusi $\mathrm{Na}-\mathrm{CMC}$ yang dihasilkan.

Nilai derajat substitusi yang dipersyaratkan dalam Food Chemical Codex III adalah tidak lebih dari 0,95 (Anon., 1981). Dengan demikian pemakaian konsentrasi sodium hidroksida $30 \%$ dan $40 \%$ pada tahap alkalinisasi memenuhi nilai derajat substitusi yang dipersyaratkan. Akan tetapi pada pemakaian sodium hidroksida $50 \%$ dan $60 \%$ (1,01 dan 1,14) dihasilkan derajat substitusi di atas nilai derajat

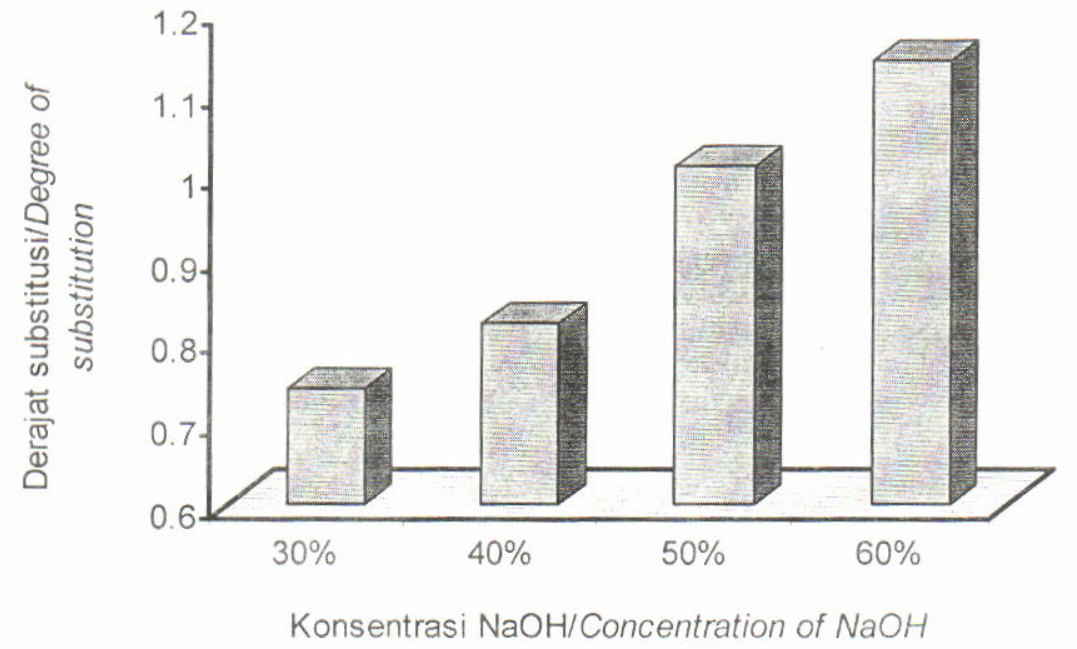

Gambar 4. Derajat substitusi Na-CMC.

Figure 4. Degree of substitution of Na-CMC.

cenderung meningkat dengan semakin tingginya pemakaian larutan $\mathrm{NaOH}$ selama proses alkalinisasi selulosa. Pada Gambar 4 dapat dilihat nilai DS untuk masing-masing perlakuan alkalinisasi selulosa.

Derajat substitusi $\mathrm{Na}-\mathrm{CMC}$ mengalami peningkatan dengan meningkatnya pemakaian konsentrasi sodium hidroksida pada tahap alkalinisasi, artinya semakin banyak gugus hidroksil pada unit anhidroglukosa yang tersubstitusikan oleh gugus karboksimetil. Terjadinya peningkatan nilai derajat substitusi ini diduga karena semakin tinggi pemakaian konsentrasi sodium hidroksida, semakin meningkat jumlah ion $\mathrm{Na}^{+}$melalui pemecahan ikatan -O dengan - H pada gugus hidroksil bebas dari selulosa, yaitu gugus hidroksil pada atom $\mathrm{C}_{6}$ atau $\mathrm{C}_{2}$. Semakin banyak jumlah selulosa yang teralkalinisasi selama perendaman dalam larutan $\mathrm{NaOH}$ maka pada waktu proses eterifikasi dengan asam monokloro asetat mengakibatkan gugus karboksimetil menjadi lebih reaktif membentuk Na-CMC. Dari hasil uji korelasi substitusi yang dipersyaratkan walaupun masih dalam batas nilai derajat substitusi $\mathrm{Na}-\mathrm{CMC}$ komersial $(0,4-$ $1,2)$.

\section{Kadar Abu}

Kadar abu menunjukkan jumlah bahan anorganik (mineral) dalam suatu bahan yang tetap tinggal pada pembakaran senyawa-senyawa organik. Komponenkomponen tersebut biasanya terdiri dari kalsium, sodium, besi, magnesium, dan mangan. Hasil pengukuran kadar abu $\mathrm{Na}-\mathrm{CMC}$ dapat dilihat pada Gambar 5.

Kadar abu Na-CMC pada penelitian ini berkisar antara 1,54-1,65\%. Kadar abu terendah ditemukan pada perlakuan alkalinisasi selulosa menggunakan larutan $\mathrm{NaOH} 30 \%$ yaitu sebesar $1,54 \%$ dan tertinggi pada perlakuan alkalinisasi menggunakan larutan $\mathrm{NaOH} 60 \%$ yaitu sebesar $1,65 \%$. Rata-rata kadar abu antar perlakuan sebesar $1,6 \%$ dengan standar deviasi 


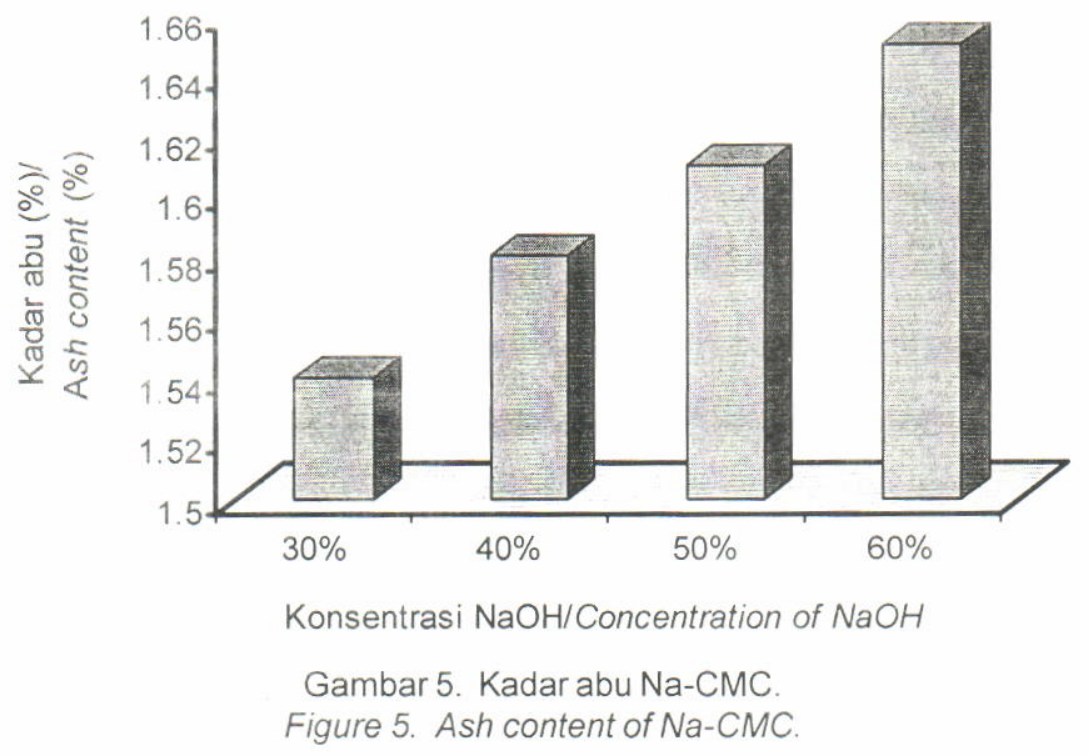

$\pm 0,035 \%$. Dari hasil uji korelasi ditemukan persamaan garis linier $Y=0,036 X+1,505$ dengan nilai $r^{2}$ sebesar 0,9969 yang berarti ada hubungan perlakuan konsentrasi $\mathrm{NaOH}$ terhadap peningkatan kadar abu yakni semakin tinggi konsentrasi larutan $\mathrm{NaOH}$ yang diberikan meningkatkan kadar abu $\mathrm{Na}-\mathrm{CMC}$ yang diperoleh. Semakin banyak $\mathrm{Na}^{+}$yang bereaksi dengan selulosa akan semakin tinggi pula sodium selulosa yang terbentuk. $\mathrm{Na}^{+}$merupakan ion yang reaktif terhadap zat-zat lain seperti gugus karboksimetil dari asam monokloro asetat. $\mathrm{Na}^{+}$merupakan mineral yang tidak hilang selama pembakaran pada suhu penentuan kadar abu oleh sebab itu peningkatan kadar abu NaCMC yang dihasilkan sangat dipengaruhi oleh jumlah $\mathrm{Na}^{+}$yang bereaksi dengan selulosa membentuk selulosa alkali. Menurut Farmakope Indonesia edisi
IV (Anon., 1995) kadar abu di dalam suatu bahan yang dipergunakan untuk keperluan farmasi adalah tidak lebih dari $2 \%$, dengan demikian kadar abu Na-CMC yang diperoleh ini masih memenuhi persyaratan yang ditetapkan dalam Farmakope Indonesia (Anon., 1995).

\section{Kadar Abu Tak Larut Asam}

Analisis kadar abu tak larut asam dilakukan untuk mengetahui jumlah atau kandungan mineral yang tidak larut dalam asam, seperti logam-logam berat. Hasil pengukuran kadar abu tak larut asam dari $\mathrm{Na}$ CMC dapat dilihat pada Gambar 6 .

Kadar abu tak larut asam pada semua perlakuan dalam pembuatan Na-CMC berkisar antara 0,21$0,24 \%$. Nilai terendah pada perlakuan alkalinisasi

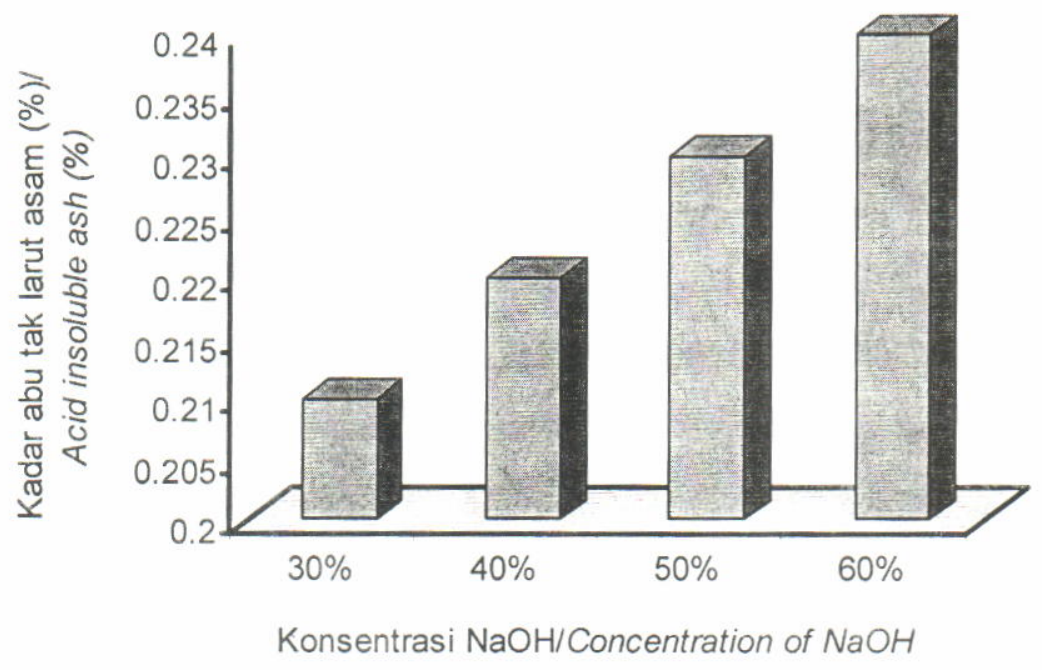

Gambar 6. Nilai kadar abu tak larut asam $\mathrm{Na}-\mathrm{CMC}$.

Figure 6. Acid insoluble ash content of $\mathrm{Na}-\mathrm{CMC}$. 
selulosa menggunakan larutan $\mathrm{NaOH} 30 \%$ sebesar $0,21 \%$ dan tertinggi ditemukan pada perlakuan alkalinisasi selulosa menggunakan larutan $\mathrm{NaOH} 60 \%$ sebesar 0,24\%. Hasil rata-rata nilai kadar abu tak larut asam antar perlakuan alkalinisasi selulosa menggunakan variasi larutan $\mathrm{NaOH}$ adalah sebesar $0,225 \%$ dengan standar deviasi sebesar 0,01, sedangkan dari hasil uji korelasi antar perlakuan ditemukan persamaan garis linier $Y=0,01 X+0,2$ dengan nilai $r^{2}$ sebesar 1 . Seperti halnya analisis kadar abu, nilai kadar abu tak larut asam yang dipersyaratkan dalam Farmakope Indonesia juga tidak boleh lebih dari $2 \%$, dengan demikian kadar abu tak larut asam Na-CMC dari hasil penelitian ini masih memenuhi persyaratan.

\section{KESIMPULAN DAN SARAN}

\section{Kesimpulan}

Dari hasil penelitian yang telah dilakukan dapat ditarik kesimpulan bahwa penggunaan larutan $\mathrm{NaOH}$ dari $30 \%$ hingga $60 \%$ memberikan pengaruh yang nyata terhadap produksi Na-CMC. Semakin tinggi larutan $\mathrm{NaOH}$ yang digunakan selama proses alkalinisasi selulosa telah menurunkan produksi $\mathrm{Na}$ CMC. Kualitas Na-CMC yang terbaik ditemukan pada perlakuan penggunaan larutan $\mathrm{NaOH} 40 \%$ ditinjau dari kadar Na-CMC 8,8\%, kelarutan $24,8 \mathrm{ml}$ air per $1 \mathrm{~g}$ $\mathrm{Na}-\mathrm{CMC}$, nilai kekentalan $35 \mathrm{cPs}$, hasil $82,6 \%$ dan derajat substitusi 0,8 .

\section{Saran}

Untuk meningkatkan rendemen Na-CMC yang diperoleh perlu dilakukan penelitian lebih lanjut mengenai pengaruh suhu dan waktu eterifikasi.

\section{DAFTAR PUSTAKA}

Anonymous. 1981. Committee on Codex Specifications. Food Chemical Codex. $3^{\text {rd }}$ ed. National Academy Press, Washington DC. p. 550-1.

Anonim. 1995. Farmakope Indonesia. Edisi IV. Direktorat Jenderal Pengawasan Obat dan Makanan. Departemen Kesehatan Republik Indonesia. 175 pp.

Anonymous. 2004. The Colombia Electronic, $6^{\text {th }}$ ed Columbia University Press. http://www.webelements. com.

Brandt, L., Hoechst, A.G. and Kalle, N. 2003. Cellulose Ethers. In Gerhartz, W. (ed.). Ullmann's Encyclopedia of Industrial Chemistry. (6): 699.

Cowd, M.A. 1991. Kimia Polimer. Penerbit ITB. Bandung. p. 2-79.

Dyess, S.E. and Emert, G.H.1978. Cellulose, new source of chemicals. In McKetta, J.J. (ed.). Encyclopedia of Chemical Processing and Design. Vol. VII. New York: Marcel Dekker Inc. p 39-49.

Fengel, D. and Wegner, G. 1984. Wood, Chemistry, UItrastructure, Reaction. Walter de Gruyer. Berlin, New York. p. 39-511.

Goplin, J.P. 2003. Bleaching of Highly Refined Cellulose. http:Ilwww. cellulose.htm.

Klug, E.D. 1995. Cellulose Ethers. In Mark, H.F., Gaylord, N.G. and Bikales, N.M. (eds.). $2^{\text {nd }}$ ed. Encyclopedia of Polymer Science and Technology. 3: 532.

Manguiat, L.S., Sabularsesolidifying, V.C. and Sabularse, D.C. 2001. Development of carboxymethyl cellulose from nata de coco. Asean Journal on Science Technology for Development. 18(2): 85-87.

Parker, S.P. 1992. Cellulose. McGraw-Hill Encyclopedia of Chemistry. $2^{\text {nd }}$ ed. New York. p. 297-305.

Wade, A. and Weller, P.J. 1994. Handbook of Pharmaceutical Excipients $2^{\text {nd }}$ ed. The Pharmaceutical Press, London. p. 78-86. 
